\title{
Prepubertal unilateral gynecomastia: a report of two cases
}

\author{
Inge A. Hoevenaren - Dina Antina Schott • \\ Barto J. Otten • Henriette C. Kroese-Deutman
}

Received: 18 March 2010 / Accepted: 17 June 2010 /Published online: 27 July 2010

(C) The Author(s) 2010. This article is published with open access at Springerlink.com

\begin{abstract}
Background Gynecomastia is defined as the presence of excessive breast tissue in males, which can appear unilateral or bilateral. Bilateral gynecomastia is frequently found in the neonatal period, early in puberty, and with increasing age. Prepubertal unilateral gynecomastia in the absence of endocrine abnormalities is extremely rare, with only a few cases in literature.

Methods We report the cases of two otherwise healthy boys of 8 and 11 years old with unilateral breast masses. No abnormalities were found on ultrasonography and all endocrine parameters were within normal limits. Treatment consisted of peripheral liposuction followed by subcutaneous partial resection of the gland, conducted through an infra-areolar incision.

Results Microscopy of the subcutaneous mastectomy specimen revealed gynecomastia without signs of malignancy. Postoperative course of both patients was uncomplicated, with no signs of recurrence of breast tissue.

Conclusions Atypical presentations of gynecomastia are often not recognized, with little attention to breast development
\end{abstract}

I. A. Hoevenaren $(\bowtie) \cdot$ H. C. Kroese-Deutman

Department of Plastic, Reconstructive and Hand Surgery,

Radboud University Nijmegen Medical Centre,

P.O. Box 9101, 6500 HB Nijmegen, The Netherlands

e-mail: I.Hoevenaren@anat.umcn.nl

D. A. Schott • B. J. Otten

Department of Endocrinology,

Radboud University Nijmegen Medical Centre,

Nijmegen, The Netherlands

Present Address:

I. A. Hoevenaren

Department of Anatomy and Embryology,

Radboud University Nijmegen Medical Centre,

Nijmegen, The Netherlands in prepubertal non-obese children. Since prepubertal gynecomastia could be a sign of possible underlying diseases, a thorough examination and further research is recommended. If there is no causal treatment, surgical resection is the therapy of first choice. Peripheral liposuction and surgical resection of the gland tissue are the mainstay of treatment. In summary, we describe two cases of prepubertal unilateral gynecomastia with a normal endocrine workup. Further research is needed to establish the pathophysiologic mechanisms of prepubertal gynecomastia, since underlying etiology in most cases remains unclear.

Keywords Unilateral gynecomastia · Prepuberty · Etiology · Surgery

\section{Introduction}

Gynecomastia is characterized by the presence of unilateral or bilateral breast tissue in males. This benign condition accounts for $60 \%$ of all disorders of the male breast $[1,2]$. While bilateral gynecomastia is common in the neonatal period, early in puberty, and with increasing age, prepubertal unilateral gynecomastia is a rare condition, with only a few cases in literature [3]. We report a unique clinical presentation of two boys with prepubertal onset of unilateral gynecomastia and discuss the etiology, workup, and therapeutic intervention.

\section{Case reports}

Patient 1

An 8-year-old boy presented with a mass beneath his right breast, slowly increasing in size over the past 8 months. 
The patient complained of tenderness of the breast mass and of being teased extensively for his enlarged breast. Family history was negative for breast malignancies, but positive for prepubertal bilateral gynecomastia in the father, as well as in two of his brothers. They underwent surgical excision at about age seven without evidence of recurrence afterwards. Past medical history revealed attention deficit hyperactivity disorder (ADHD), for which the patient was treated with Methylphenidate $30 \mathrm{mg} /$ day and Melatonin $5 \mathrm{mg} /$ day. No other drugs or dermal applications were used. Physical examination showed a healthy-appearing boy, $136 \mathrm{~cm}$ tall (SDS 0), without accelerated growth velocity, weighing $30 \mathrm{~kg}$ (SDS 0) with a body mass index (BMI) of 16.2 (SDS 1). Palpation of the right breast revealed a firm mobile mass measuring approximately $8 \mathrm{~cm}$ in diameter, with tenderness on deep palpation, Tanner stage III [4]. The right nipple-areola complex was also enlarged, measuring $1.5 \mathrm{~cm}$ compared to $1 \mathrm{~cm}$ on the left. There was no history or sign of galactorrhea and there were no physical findings indicating onset of puberty. A summary of all endocrine parameters tested with corresponding results is given in Table 1. All parameters were found to be within normal limits. Ultrasound examination of the right breast showed glandular tissue without cysts or signs of malignancy. Surgery (conducted by HKD and IAH) under general anesthesia consisted of peripheral liposuction (with the $2 \mathrm{~mm}$ powerassisted lipoplasty (PAL) liposuction system) and subcutaneous partial resection of the gland, conducted through an infraareolar incision. The dissected gland specimen measured $2.5 \times 1.6 \times 0.5 \mathrm{~cm}$ and weighed $15 \mathrm{~g}$. The resulting depression was reconstructed by leaving part of the glandular tissue in situ and repositioning it, in order to attain a symmetrical result. Pathologic examination revealed normal glandular breast tissue, without evidence of malignancy. Microscopy of the subcutaneous mastectomy specimen showed fibrotic breast tissue with mammary ducts with epithelial hyperplasia, periductal cellular stroma, and stroma hyperplasia. The concluding diagnosis was florid gynecomastia. Recovery from the surgery was uneventful. At a postoperative clinical evaluation 8 months later, no signs of recent breast development were seen. The patient is currently planned for a minor correction under local anesthesia of a minimal residual areolar swelling.

\section{Patient 2}

An 11-year-old boy presented with a 12-month history of left breast enlargement. The patient also complained of tenderness of the breast mass and of great inconvenience in everyday life. In this case, there was no family history of breast malignancies or gynecomastia. No drugs or dermal applications were used. Physical examination showed a healthy-appearing lively boy. The patient was $138 \mathrm{~cm}$ tall (SDS -1) without accelerated growth velocity, weighing $32 \mathrm{~kg}$ (SDS 0) with a BMI of 16.8 (SDS 0). Palpation of the left breast revealed a firm mass measuring approximately $5 \mathrm{~cm}$ in diameter, with tenderness on deep palpation, Tanner stage III. There was a pronounced asymmetry of the breast, with a normal-appearing right breast (Fig. 1a). No history or sign of galactorrhea existed, and there were no physical findings indicating onset of puberty. A summary of all endocrine parameters tested with corresponding results is given in Table 1. All parameters were found to be within normal limits. Ultrasound examination of the right breast showed retro-aureolar glandular tissue with normal aspects and swelling containing subcutaneous fat tissue. An abdominal computed tomography scan excluded any estrogen-producing tumor. Surgery (conducted by HKD)
Table 1 Endocrinologic findings

TSH thyroid-stimulating hormone, FT4 free thyroxine, $L H$ luteinizing hormone, $F S H$ follicle-stimulating hormone, $h C G$ human chorionic genodotropin, $17 \mathrm{OHP}$ 17-hydroxy-progesterone, $S H B G$ sex hormone-binding globulin, DHEAS dehydroepiandrosterone

\begin{tabular}{lccc}
\hline Endocrine study & Patient & Patient 2 & Normal reference range \\
\hline TSH & 1.0 & 1.2 & $0.4-4.0 \mathrm{mU} / \mathrm{L}$ \\
FT4 & 13.5 & 12.3 & $8-22 \mathrm{pmol} / \mathrm{L}$ \\
LH & $<0.15$ & $<0.15$ & $<0.15-1.3 \mathrm{U} / \mathrm{L}$ \\
FSH & 0.76 & 0.94 & $<0.15-3.7 \mathrm{U} / \mathrm{L}$ \\
Estradiol (E2) & $<10$ & 30 & $<30-70 \mathrm{pmol} / \mathrm{L}$ \\
Estrone & 110 & 210 & $65-220 \mathrm{pmol} / \mathrm{L}$ \\
Testosterone & $<0.02$ & 0.27 & $0.03-0.65 \mathrm{nmol} / \mathrm{L}$ \\
hCG & $<1.0$ & $<1.0$ & $<1.0 \mathrm{ng} / \mathrm{ml}$ \\
Prolactine & 98 & 128 & $80-660 \mathrm{mU} / \mathrm{L}$ \\
17OHP & 0.3 & 1.0 & $0.2-7.4 \mathrm{nmol} / \mathrm{L}$ \\
SHBG & 123 & 117 & $30-210 \mathrm{nmol} / 1$ \\
Androstenedione & $<0.05$ & 0.65 & $0.2-2.4 \mathrm{nmol} / \mathrm{L}$ \\
DHEAS & $<0.4$ & 1.18 & $0.29-1.90 \mu \mathrm{mol} / 1$ \\
Estrogen receptor & 19 & $<10$ & $<20 \mathrm{fmol} / \mathrm{mg}$ \\
Progesterone receptor & 13 & 10 & $<20 \mathrm{fmol} / \mathrm{mg}$ \\
\hline
\end{tabular}



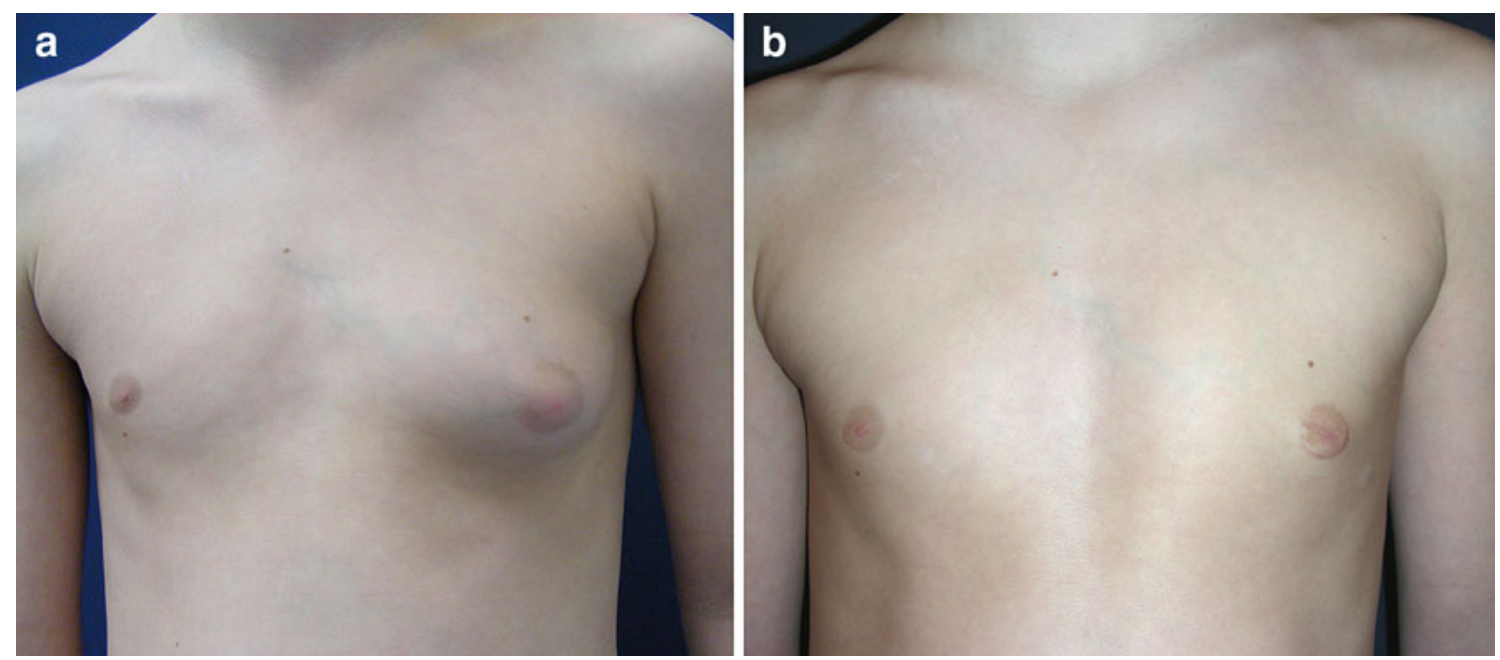

Fig. 1 a An 11-year-old boy with unilateral gynecomastia of his left breast. b The same boy at an 11-month postoperative evaluation, without any signs of breast development

under general anesthesia consisted of peripheral liposuction (with the $2 \mathrm{~mm}$ PAL liposuction system) and subcutaneous partial resection of the gland, conducted through an infraareolar incision. The specimen dissected measured 5.0 $\times 3.0 \times$ $2.5 \mathrm{~cm}$. Pathologic examination revealed normal glandular breast tissue, without evidence of malignancy. Microscopy of the subcutaneous mastectomy specimen showed mammary ducts with hypertrophic ductuli and mild lymphocytic infiltrates lining the ducts. The concluding diagnosis was normal gynecomastia tissue. Recovery was uneventful. At a postoperative clinical evaluation 11 months later, there were no signs of breast development (Fig. 1b).

\section{Discussion}

Gynecomastia is a condition in which the glandular components of the male breast proliferate, resulting in an enlargement of one or both breasts. In the age distribution, three distinct peaks are identified. The first is found in the neonatal period, in which palpable breast tissue develops in $60 \%$ to $90 \%$ of all newborns due to transfer of estrogens across the placenta. The second peak occurs during puberty, as a result of an imbalance between estrogens and androgens within the breast tissue. The last peak is found in the adult population, with the highest prevalence among 50 - to 80 -yearold males $[1,3]$. Common known causes for gynecomastia in adults include liver disease, as well as the use of drugs such as digitalis and tricyclic antidepressants [5]. In contrast to gynecomastia in adolescent boys and adult men, prepubertal gynecomastia is rare. A specific cause is hardly ever identified, and in $90 \%$ of patients, prepubertal gynecomastia is classified as idiopathic [2,6]. Known causes of breast enlargement in children are diverse $[3,6-8]$. Therefore, further exploration of the etiology is advised, particularly to rule out any endocrine or malignant abnormalities. A variety of endocrinopathies, mostly as a result of an increased ratio of circulating estrogens to androgens, induce stimulation of breast tissue leading to gynecomastia. Calzada et al. showed that the presence of hormone receptors in gynecomastia may provide a setting favorable for mammary glands to develop gynecomastia [9]. In patient 1 , there were low levels of both receptors and, in patient 2 , only the progesterone receptor was detected. We conclude that the gynecomastia in our patients was not mediated by an abnormal increase in the numbers of these receptors. The family history of our first patient revealed gynecomastia on the father's side. Stratakis et al. described increased extraglandular aromatization of androgens to cause the unusual entity of familial gynecomastia, named aromatase excess syndrome [10]. This syndrome has been correlated to serum estradiol and estrone excess, which were within normal limits in both of our patients. Therefore, a mild aromatase excess syndrome could be excluded as a cause of the prepubertal gynecomastia and familial occurrence. None of our patients were exposed to exogenous estrogens. However, our first patient was using Melatonin, of which in literature only one case is reported. The case described a possible relationship of the usage of this drug and a painful bilateral gynecomastia in an adult male [11], making the relationship between this drug and gynecomastia in our first patient very unlikely. Furthermore, obesity is documented in $31 \%$ of the boys, with excessive fat tissue as a possible cause of prepubertal gynecomastia [3]. Increased adipose tissue causes an increased aromatization of mostly testosterone in adipose tissue, leading to an imbalance between estradiol and testosterone levels. Our patients had no signs of being overweight; therefore, obesity was excluded as the etiology for the gynecomastia. 
In summary, atypical presentations of gynecomastia are frequently underappreciated, with little attention to breast enlargement in the nonobese prepubertal boy. Since prepubertal gynecomastia could be a sign of possible underlying diseases, a thorough examination and further research is recommended. If a reversible cause can be excluded, peripheral liposuction in combination with surgical resection of the gland tissue by an infra-areolar approach is the first therapy of choice. We report two rare cases of prepubertal unilateral gynecomastia, in whom the cause of the gynecomastia remains unclear, while none of the above discussed causes could be identified.

Open Access This article is distributed under the terms of the Creative Commons Attribution Noncommercial License which permits any noncommercial use, distribution, and reproduction in any medium, provided the original author(s) and source are credited.

\section{References}

1. Braunstein GD (1993) Gynecomastia. N Engl J Med 328(7):490495
2. Cho YR, Jones S, Gosain AK (2008) Neurofibromatosis: a cause of prepubertal gynecomastia. Plast Reconstr Surg 121 (3): $34 \mathrm{e}-40 \mathrm{e}$

3. Einav-Bachar R, Phillip M, Aurbach-Klipper Y, Lazar L (2004) Prepubertal gynaecomastia: aetiology, course and outcome. Clin Endocrinol 61(1):55-60

4. Marshall WA, Tanner JM (1970) Variations in the pattern of pubertal changes in boys. Arch Dis Child 45(239):13-23

5. Harigopal M, Murray MP, Rosen PP, Shin SJ (2005) Prepubertal gynecomastia with lobular differentiation. Breast J 11(1):48-51

6. Henley DV, Lipson N, Korach KS, Bloch CA (2007) Prepubertal gynecomastia linked to lavender and tea tree oils. N Engl J Med 356(5):479-485

7. Ersoy B, Yoleri L, Riza Kandiloğglu A (2002) Unilateral galactocele in a male infant. Plast Reconstr Surg 109(1):401-402

8. Kauf E (1998) Gynecomastia in childhood: pathologic causes unusual but serious. Fortschr Med 116(35-36):23-26

9. Calzada L, Torres-Calleja J, Martinez JM, Pedrón N (2001) Measurement of androgen and estrogen receptors in breast tissue from subjects with anabolic steroid-dependent gynecomastia. Life Sci 69(13):1465-1469

10. Stratakis CA, Vottero A, Brodie A et al (1998) The aromatase excess syndrome is associated with feminization of both sexes and autosomal dominant transmission of aberrant P450 aromatase gene transcription. J Clin Endocrinol Metab 83(4):1348-1357

11. De Bleecker JL, Lamont BH, Verstraete AG, Schelfhout VJ (1999) Melatonin and painful gynecomastia. Neurology 53 (2):435-436 